\title{
Evolution of the Functional Resonance Analysis Method (FRAM) through the combi- nation with other methods
}

\author{
M.C. Pardo-Ferreira, M. Martínez-Rojas, F. Salguero-Caparrós, J. C. Rubio-Romero
}

Recibido: 21 de Octubre de 2018 / Aceptado: 27 de Octubre de 2018

\begin{abstract}
Traditionally, simple and complex linear models were used to analyze accidents and find their causes. The Resilience Engineering breaks with the traditional way of understanding safety focused on things that go wrong. In this way, the concept of safety is redefined to focus on things that go well. The new paradigm of Resilience Engineering emphasizes that when things go well in difficult circumstances, it is mainly due to the ability of workers to adapt, that is, their ability to recognize and absorb unexpected changes and events. In this new context, Functional Resonance Analysis Method enables to model how a system works and to understand the variability in daily performance. The objective of this research study is to present the main approaches that combine other methods with FRAM with the aim of improving it, as for example: Monte Carlo simulation, Fuzzy Logic theory, Model Checking, Analytical Hierarchical Process methodologies and Abstraction Hierarchy. Notice that the present study develops a non-exhaustive review of the methods that appears most frequently in the scientific Literature. The search process has been carried out in the main scientific databases such as Web of Knowledge, Science Direct or Google Scholar since they are identified as relevant to the research domain. In order to obtain adequate results concerning the objective of this work, we consider "Functional Resonance Analysis Method" as terms to perform the search in the title, abstract and keyword fields. After the data collection process, a total of 22 documents were obtained. Subsequently, all the retrieved documents were filtered by selecting those publications that had the purpose of combining the FRAM with another method to define the function variability in a semi-quantitative or quantitative manner. Then, after this filtering process, 18 studies were analysed and presented from diverse perspectives. Firstly, an analysis was conducted to explore the evolution of this research domain over time. As a result of this analysis, a growing trend in the publication of research is observed, both journal documents and conference documents. Secondly, an analysis concerning the sector where the study is focused is detailed since all the analyzed studies included an application example of their proposal. In this sense, the aviation sector was the one that appeared most frequently, followed by the maritime sector. Thirdly, the distribution of analysed studies on the basis of the country of authors has been presented, being Italy and China the reference countries in this research domain. Following, an analysis in relation to the journals where the documents are published is conducted. Finally, the proposals were grouped according to the different approaches that were combined with FRAM. As a general conclusion, the analysis of the new FRAM approaches shows that all the authors coincide in preserving the theoretical basis of FRAM for modeling complex systems. Despite this, there is still no approach that prevails over others and future research should continue to advance the evolution the Functional Resonance Analysis Method with the aim to facilitate the risk assessments in complex systems.
\end{abstract}

\section{Keywords}

Functional Resonance Analysis Method; Resilience Engineering, Complex systems; Risk assessment; Safety.

\section{Introduction}

The organizations themselves have evolved over time and with them the models of accidents (Stoop and Dekker 2012). Initially, simple linear models (Heinrich, 1931) were used to understand accidents and find their causes. Subsequently, the organizations became more complex and complex linear models (Reason, 1997) emerged. Currently, linear models, simple or complex, do not respond to reality that is fundamentally non-linear as well as complex. For this reason, the vision of the accident arise as a non-linear phenomenon that emerges from a complex system and that gives rise to systemic models of accidents or non-linear models. These models are used in complex systems such as nuclear power plants, aviation, railway, manufacturing process, maritime y Administración de Empresas. Universidad de Málaga.

Calle Doctor Ortiz Ramos s/n. 29071, Málaga 
systems... The systemic models recognizes that complex system performance always is variable, both because of the variability of the environment, or exogenous variability, and the internal variability of the system, or endogenous variability (Hollnagel et al., 2007). The accident "emerges" from normality (Perrow, 1984), due to concurrent events that "resonate", and are not "caused" by a simple chain of errors. Within the framework of this new conception, the Resilience Engineering (RE) is developed. The RE is a new paradigm of safety management that focuses on how to help people cope with complexity under pressure to achieve success (Hollnagel et al., 2007). The RE focuses attention on things that go well rather than on things that go wrong and understand the variability in daily performance as something positive and necessary to achieve success.

In order to model the systems according to this new paradigm, Hollnagel (2012) develops the Functional Resonance Analysis Method (FRAM). This method is focus on describing the work-as-done rather than the work-as-imagined. Thus, FRAM can be used in practice to model how a system works as a basis for understanding adverse events.

FRAM is based on a complex non-linear model, assuming that accidents are the result of unexpected combinations (resonance) of normal variability, couplings between functions that resonate, but that are also not random, although it cannot be attributed to a simple combination linear of linked causes (Hollnagel, 2012).

According to this point of view, it is important to monitor the performance and dampen the variability between the system functions, so that organizations develop a resilient performance. Of course, it requires the ability to anticipate future events continuously. The conditions of performance in the systems are changing. Limitations in the availability of time and resources as well as other pressures derived from the organization and the environment are common. Therefore, it is necessary to make sacrifices between thoroughness and efficiency. This balance is called by Hollnagel as Principle of Efficiency-Thoroughness Trade-Off (ETTO) (Hollnagel, 2004). These adjustments are a sine qua non condition, so the variability in performance is necessary although it must be managed properly (Rubio-Romero et al., 2017).

FRAM is founded on four principles: the principle of equivalence of failures and successes; principle of the importance of making approximate adjustments to match the conditions of the system; principle of the reality of the emergency on the variability of the normal performance; and principle of functional resonance which defines the dependencies in the system rather than cause-effect relationships (Hollnagel, 2012).

This method characterizes complex systems based on the performed functions instead of how the system is structured. The FRAM involves the following steps proposed by Hollnagel (2012):

- $\quad$ Step 0: Defining the purpose of FRAM Analysis. FRAM can be applied with a retrospective approach, such as accident analysis, or with a prospective approach, such as risk assessment or process design.

- Step 1: Identify and describe the functions. The functions will be characterized by six aspects or variables (input, output, time, control, precondition, and resource) represented in Figure 1.
Figure 1 Hexagon representing each function (Hollnagel, 2012)

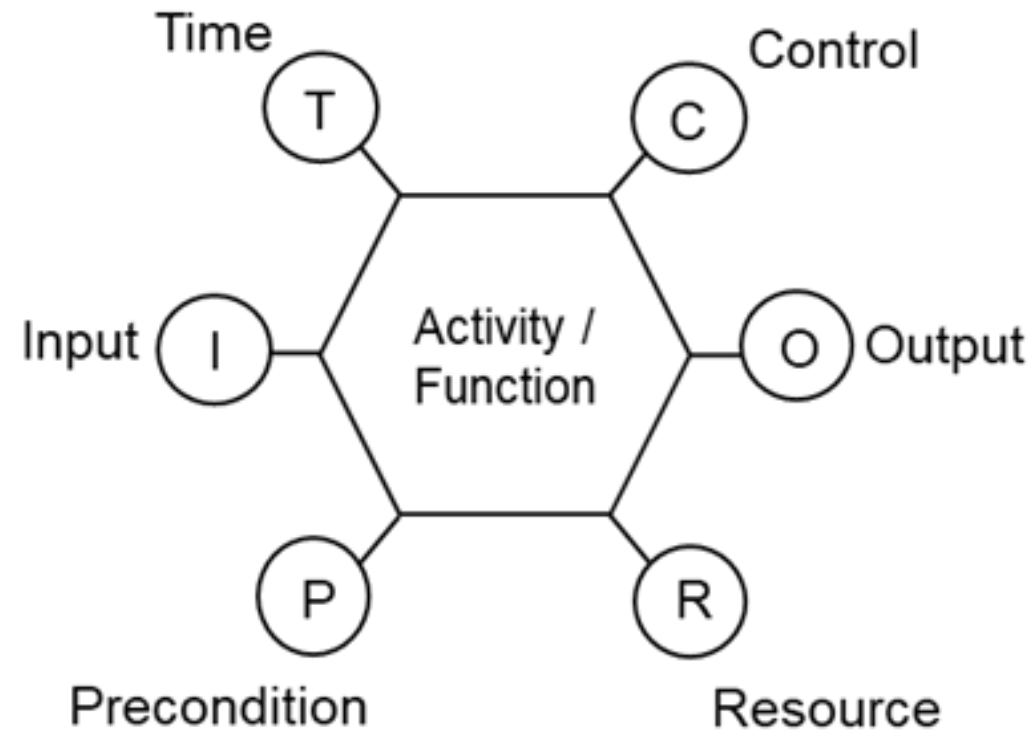


- $\quad$ Step 2: Identification of variability. This step focuses on analyzing the individual variability of each function, both internal and external. The potential variability as well as the actual variability should be considered.

- $\quad$ Step 3: Aggregation of variability. The propagation of the variability through couplings of the upstream and downstream functions is analyzed.

- Step 4: Consequences of the analysis. Based on the results of the previous steps, measures are identified to manage the performance variability, either barriers and control mechanisms or monitoring and dampening the variability.

The FRAM model of a system allows to understand how everyday work is performed and how failure can emerge from performance variability. Based on this, different measures and controls can be established to strengthen the capacity of the system to respond to both expected and unexpected events. However, building a FRAM model may become a difficult task (Patriarca et al., 2017b). Therefore, studies focused on enhancing FRAM to facilitate its application, have begun to develop. The aim of this study is to present the main approaches to enhance the FRAM by combining it with other methods.

After this introduction, the remainder of the paper is structured as follows. Section 2 is devoted to explain the methodological approach to analyse the current state of literature. Section 3 details the results according to different analysed variables. Finally, Section 4 presents the conclusions.

\section{Methodology}

This study presents the preliminary results on the advances in the research focused on the evolution of the FRAM through the combination with other methods, which make possible to define the function variability in a semi-quantitative or quantitative manner. For this reason, the present study develops a non-exhaustive review of the methods that appears most frequently in the scientific literature.

Firstly, the search process is described and secondly, the qualitative process for document filtering is detailed. The search process has been carried out in the main scientific databases such as Web of Knowledge, Science Direct or
Google Scholar since they are identified as relevant to the research domain. These databases enable to search through different fields such as title, author, Keywords, abstract, references, etc. as well as to select research domains, publication years, type of documents, etc. In this work, we focus on the title, abstract and keyword as searching fields. Therefore, in order to obtain adequate results concerning the objective of this work, we consider "Functional Resonance Analysis Method" as terms to perform the search on the basis of the mentioned fields. After this data collection process, duplicate documents can be obtained, either by performing different queries on the same database or because a same document can be indexed in different databases. Therefore, a removal process is necessary in order to eliminate duplicated records. A total of 22 documents were obtained.

Subsequently, all the retrieved documents were filtered by selecting those publications that had the purpose of combining the FRAM with another method to define the function variability in a semi-quantitative or quantitative manner. Notice that some documents apply methods to enhance the visualization with the aim to facilitate analysis, but they are beyond the scope of this work (Ricardo et al., 2018, Lundberg $\&$ Woltjer, 2013). Then, after this filtering process, 18 studies were analysed and presented in this study. Next section presents the analysis of results from diverse perspectives.

\section{Results}

This section presents the results of the literature review from diverse perspectives. Firstly, the analysis of the 18 studies is developed from a general point of view. Secondly, the records are grouped according to the main methods used to enhance the FRAM in the analysed documents, which are: Monte Carlo simulation, Fuzzy Logic theory, Model Checking, Analytical Hierarchical Process methodologies and Abstraction Hierarchy.

The studies analysed were published between 2015 and 2017. Thus, Figure 2 shows a growing trend in the publication of research aimed at enhancing the FRAM. Despite this, there is still no approach to that prevails over others, since they are all recent and it is necessary to continue working on them. Fig. 2 also distinguishes the type of document, namely, conference document or journal document. As can be seen, the number of journal document has grown considerably in the last year. 
Figure 2 Distribution of studies per year

All the studies analysed included an application example of the proposed new approach focus on a specific sector. According to Figure 3, the aviation sector was the one that appeared most frequently, followed by the maritime sector. In

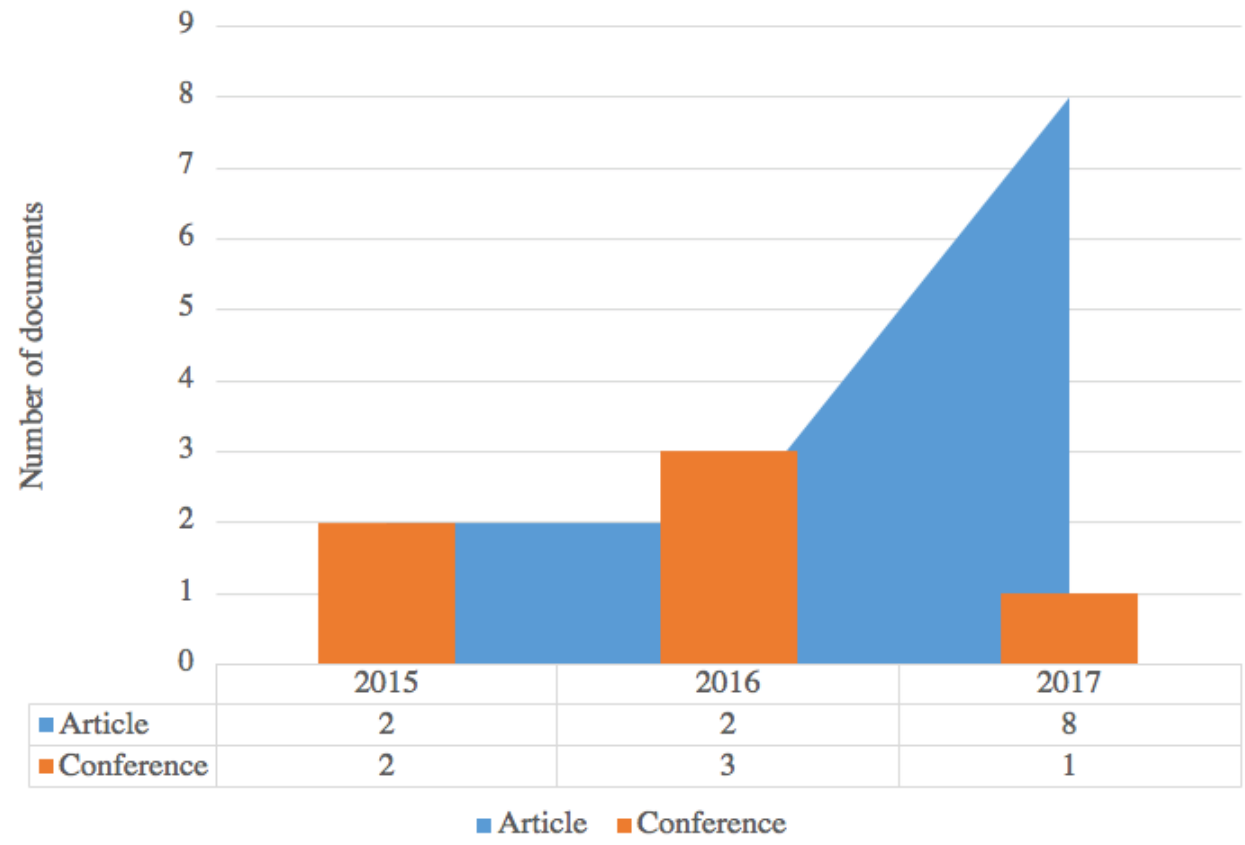

the latter case, two of the three application examples used the Herald of Free Enterprise car ferry disaster as a case study, previously analysed by Hollnagel (2012).
Figure 3 Distribution of studies by sector

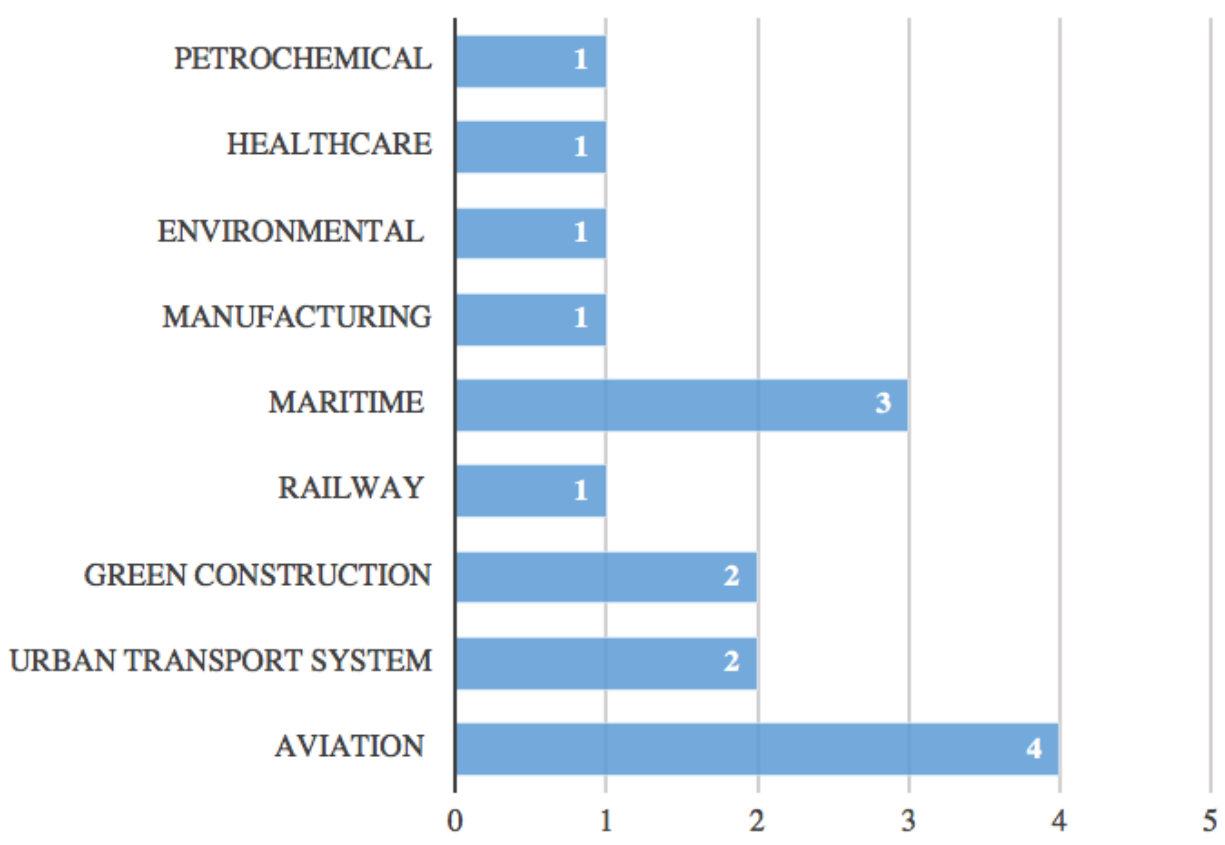


Additionally, from a general perspective, the distribution of studies according to the country of authors has been analysed. As can be seen in Figure 4, almost half of the analysed documents correspond to authors from Italy. The second country with the largest number of documents is China
Figure 4 Distribution of studies ac-

cording to the author's country.
Studies by author's country

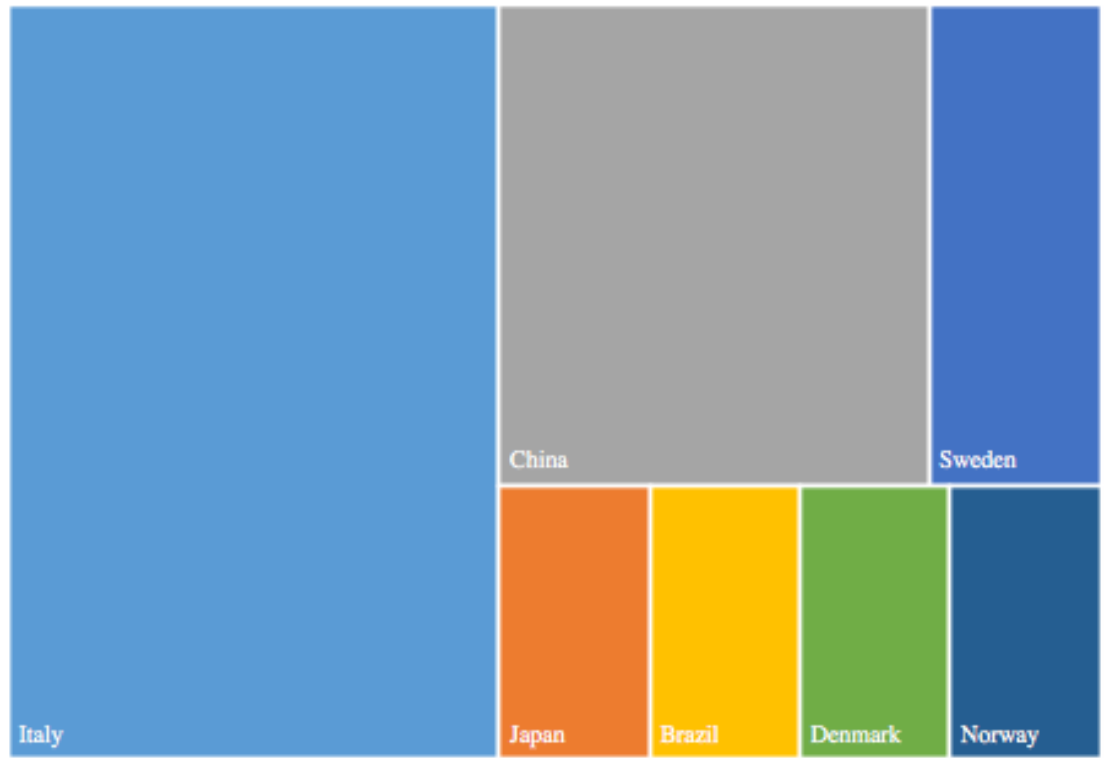

Table 1 presents the journals in which documents have been published. Additionally, this table details 2017 Journal Citation Reports (JCR) Impact Factor which reflects the average number of citations and allows to measure the quality of the journal. As can be appreciated in the table, most of the recorded articles are published in journals ranked in the first or third quartile.
Table 1 Reference journals for the research topic and their impact factor

\begin{tabular}{lccc}
\hline Journal & No. Doc & JCR-IF (2017) & Quartile \\
\hline $\begin{array}{l}\text { Cognition Technology } \\
\text { Work }\end{array}$ & 4 & 1.260 & Q3 \\
\hline $\begin{array}{l}\text { Safety Science } \\
\text { Environmental Impact As- }\end{array}$ & 3 & 2.835 & Q1 \\
\hline $\begin{array}{l}\text { ACssment Review } \\
\text { net Technology }\end{array}$ & 1 & 3.054 & Q1 \\
\hline $\begin{array}{l}\text { Mathematical Problems in } \\
\text { Engineering }\end{array}$ & 1 & 1.727 & Q2 \\
\hline $\begin{array}{l}\text { Reliability Engineering } \\
\text { System Safety }\end{array}$ & 1 & 0.644 & Q3 \\
\hline
\end{tabular}

With the aim of conducting a more in-depth analysis, the categories of these journals have been extracted in order to explore the areas of knowledge in which this research topic has a greater impact. Notice that a journal might have asso- ciated with more than one subject category. Table 2 presents the categories in which the journals of Table 1 are indexed. The results provide quantitative evidence about the engineering and management character of this research. 
Table 2 Indexed categories of journal in Table 1.

\begin{tabular}{cc}
\hline Subject categories & No. Journals \\
\hline Engineering, Industrial & 5 \\
\hline Operations Research \& Management & 4 \\
\hline Environmental Studies & \\
\hline Computer Science, Information Science & 1 \\
\hline Engineering, Multidisciplinary & 1 \\
\hline Computer Science, Software Engineering & 1 \\
\hline Mathematics, Interdisciplinary Application & 1 \\
\hline
\end{tabular}

Following, Table 3 shows a summary of the main characteristics of the analysed studies. It is noted that Patriarca has become one of the most prolific authors in this area. It highlights that there are other methods that have been combined with the FRAM such as Anticipatory Failure Determination method (Jensen and Aven, 2017), Leading Indicator Identification method (Raben and Hollnagel, 2017) or Matrix Representation (Patriarca et al., 2018) that will be analysed in future stages of this investigation.

\subsection{Monte Carlo simulation}

Patriarca et al. (2017c) proposes evolve the FRAM by combining it with Monte Carlos simulation. This method allows to use a probabilistic approach to define critical functions. Thus, Patriarca et al. (2017c) defines a semi-quantitative approach to FRAM, which makes it possible to define quantitatively the function variability. For this purpose, a Subject Matter Experts (SME) collaborate to assign weights to define the performance variability. Based on this, a discrete probability distribution is defined for the variability of each function. Subsequently, Patriarca et al. (2017d) use this semi-quantitative FRAM to assess environmental risks in a sinter plant. Emphasizing that it is the first study that uses FRAM in an environmental context. This case study validates their research, showing the benefits in terms of identifying potential critical activities, related mitigating actions and comprehensive environmental monitoring indicators. 
M.C. Pardo-Ferreira et al. / Dirección y Organización 68 (2019) 41-50

Table 3 Main characteristics of the studies analysed

\begin{tabular}{|c|c|c|c|}
\hline & Objective & $\begin{array}{l}\text { Methods combined with } \\
\text { FRAM }\end{array}$ & Case study \\
\hline Patriarca et al. (2017c) & $\begin{array}{l}\text { To facilitate the safety analy- } \\
\text { sis in complex systems }\end{array}$ & Monte Carlos simulation & Air Traffic Management \\
\hline Patriarca et al. (2017d) & $\begin{array}{l}\text { To validate their research and } \\
\text { to show the benefits of the } \\
\text { new approach }\end{array}$ & Monte Carlos simulation & $\begin{array}{l}\text { Environmental risk auditing } \\
\text { in a sinter plant }\end{array}$ \\
\hline Hirose et al. (2016) & $\begin{array}{l}\text { To obtain a method for eval- } \\
\text { uating the dynamics of the } \\
\text { growing disturbances }\end{array}$ & $\begin{array}{l}\text { Cognitive reliability and error } \\
\text { analysis method and Fuzzy } \\
\text { Logic }\end{array}$ & Air crash accident \\
\hline Bellini et al. (2017) & $\begin{array}{l}\text { To quantify the functional } \\
\text { variability and the dampen- } \\
\text { ing capacity }\end{array}$ & Fuzzy Logic & Urban Transport System \\
\hline Zheng and Tian (2015) & $\begin{array}{l}\text { To make the accident analysis } \\
\text { more effective }\end{array}$ & $\begin{array}{l}\text { Finite State Machine (FSM) } \\
\text { and Model Checking }\end{array}$ & $\begin{array}{l}\text { Herald of Free Enterprise car } \\
\text { ferry disaster }\end{array}$ \\
\hline Zheng et al. (2016) & $\begin{array}{l}\text { To redefine the operational } \\
\text { guidelines }\end{array}$ & Model checker SPIN & Manufacturing processes \\
\hline Yang et al. (2017) & $\begin{array}{l}\text { To facilitate the identification } \\
\text { of hazards with greater rigor } \\
\text { and efficiency }\end{array}$ & Model checker SPIN & Air Traffic Management \\
\hline Duan et al. (2015) & $\begin{array}{l}\text { To enhance FRAM to explore } \\
\text { the paths of hazard evolution. }\end{array}$ & $\begin{array}{l}\text { State Transition Diagram and } \\
\text { Model Checking }\end{array}$ & Typical air accident analysis \\
\hline Tian et al. (2016) & $\begin{array}{l}\text { To develop an approach } \\
\text { based on FRAM for hazard } \\
\text { identification called FRAM- } \\
\text { based analysis (FRAMA) }\end{array}$ & $\begin{array}{l}\text { Model Checking Tools Pro- } \\
\text { cess Analysis Toolkit }\end{array}$ & $\begin{array}{l}\text { Herald of Free Enterprise car } \\
\text { ferry disaster }\end{array}$ \\
\hline Rosa et al. (2015) & $\begin{array}{l}\text { To recognize situations with- } \\
\text { out control and to establish } \\
\text { the necessary control and } \\
\text { monitoring measures }\end{array}$ & $\begin{array}{l}\text { Analytic Hierarchy Process } \\
\text { methodologies }\end{array}$ & Green construction industry \\
\hline Rosa et al. (2017) & $\begin{array}{l}\text { To demonstrate an alternative } \\
\text { approach to risk assessment } \\
\text { that fits the sustainable safety } \\
\text { approach in the green con- } \\
\text { struction. }\end{array}$ & $\begin{array}{l}\text { Analytic Hierarchy Process } \\
\text { methodologies }\end{array}$ & Green construction industry \\
\hline Haddad et al. (2015) & $\begin{array}{l}\text { To support the identification } \\
\text { of functional performance } \\
\text { variability }\end{array}$ & $\begin{array}{l}\text { Analytic Hierarchy Process } \\
\text { methodologies }\end{array}$ & Construction sustainability \\
\hline Bellini et al. (2016) & $\begin{array}{l}\text { To manage critical infra- } \\
\text { structure resilience through a } \\
\text { more complex and expressive } \\
\text { model: Resilience Decision } \\
\text { Support (ResilienceDS). }\end{array}$ & $\begin{array}{l}\text { Bayesian Decision Support } \\
\text { process and Analytic Hierar- } \\
\text { chy Process paradigm }\end{array}$ & Urban Transport System \\
\hline Patriarca et al. (2017b) & $\begin{array}{l}\text { To allows systemic functional } \\
\text { analysis at di } \square \text { erent levels of } \\
\text { abstraction and among di } \square \text { er- } \\
\text { ent agents, for the develop- } \\
\text { ment of a systemic multi-lay- } \\
\text { er functional structure }\end{array}$ & $\begin{array}{l}\text { Abstraction/Agency frame- } \\
\text { work (Rasmussen's Abstrac- } \\
\text { tion Hierarchy adaptation) }\end{array}$ & Railway \\
\hline Patriarca et al. (2017a) & $\begin{array}{l}\text { To understand and contribute } \\
\text { with new perspectives to the } \\
\text { complexity of processes and } \\
\text { to confirms the benefits of the } \\
\text { new approach }\end{array}$ & $\begin{array}{l}\text { Abstraction/Agency frame- } \\
\text { work (Rasmussen's Abstrac- } \\
\text { tion Hierarchy adaptation) }\end{array}$ & Maritime operations \\
\hline De Felice et al. (2016) & $\begin{array}{l}\text { To propose a new innovative } \\
\text { approach to evaluate the vari- } \\
\text { ability of the human error }\end{array}$ & Human Reliability Analysis & Petrochemical \\
\hline Jensen et al. (2017) & $\begin{array}{l}\text { To present a new hazard/ } \\
\text { threat identification method }\end{array}$ & $\begin{array}{l}\text { Anticipatory Failure Deter- } \\
\text { mination }\end{array}$ & \\
\hline
\end{tabular}




\subsection{Fuzzy Logic theory}

Hirose et al. (2016) and Bellini et al. (2017) carried out research focused on evolving FRAM with a qualitative approach by combining it with Fuzzy Logic. On the one hand, Hirose et al. (2016) use the research of Ung (2015), which adapts the cognitive reliability and error analysis method (CREAM) (Hollnagel, 1998) using the Fuzzy Logic to obtain a weighted CREAM model. Based on this model, Hirose et al. (2016) proposes a fuzzy CREAM methodology integrated with the FRAM to obtain a method for evaluating the dynamics of the growing disturbances. This new FRAM approach used the probability of action failure, which is the probability that the human performance will fail under certain circumstances, to define the variability scale of the functions. Thus, a quantitative value of the functional resonance is obtained. The process should be based on statistical data and/or the knowledge of experts. On the other hand, Bellini et al. (2017) propose a method to quantify the functional variability and the dampening capacity. For this purpose, Bellini et al. (2017) define the concept of Variability Rate (VR) as the quantification of the amount of function performance variability in upstream exceeding the function dampening capacity of a downstream function. In that way, the FRAM variability observations are encoded with fuzzy logic-based method to translate perception-based observations into a quantification of the VR. This proposed method is based on expert judgment when quantitative data are not available.

\subsection{Model Checking}

The studies focused on proposing the adaptation of the FRAM through the combination with Model Checking are the most numerous in the research carried out to enhance the FRAM. Five publications were found in this regard (Duan et al., 2015; Tian et al., 2016; Yang et al., 2017; Zheng et al., 2016; Zheng and Tian, 2015). All of them use the model checking to examine all the paths through which the functions can be coupled, leading to functional resonance and deviations or failures of the performance of the system. After analysing each of them, it can be concluded that, in general, the main steps followed are similar. The differences appear in the process followed to translate in a mathematical model the functions defined qualitatively by FRAM, the mechanism to establish the safety constraints and the type of model checking used. However, all of them show that the combination of Model Checking and FRAM facilitates the practical application of FRAM, since the paths of propagation of variability are examined automatically.

\subsection{Analytical Hierarchical Process methodol- ogies}

The FRAM has also been combined with Analytic Hierarchy Process methodologies which are a type of multi-criteria decision-making methods. Similar to Model Checking, the enhancement of FRAM with AHP is intended to recognize situations where developments could be without control and establish the necessary control and monitoring measures. AHP establishes a tree composed of different levels, that is, implements a multi-level hierarchy in the model. Rosa et al. (2015) and Rosa et al. (2017) propose a hierarchical structure of AHP created for the current or potential variability of the FRAM functions. The AHP is applied to quantify the output variability of each function based on experts' and/or workers' judgments. Bellini et al. (2016) develops a collaborative tool extending the FRAM model: Resilience Decision Support (ResilienceDS). In this case, the outputs of a FRAM function are modeled as a Bayesian Decision Support process and the AHP paradigm has been integrated with the Italian Flag representation structure. Again, the data and the experts' assessment are used.

\subsection{Abstraction Hierarchy}

Patriarca et al. (2017b) again proposes to evolve FRAM, but this time combining it with Rasmussen's Abstraction Hierarchy (AH). For this purpose, Patriarca et al. (2017b) adapt $\mathrm{AH}$ and propose an innovative Abstraction/Agency framework. Therefore, a multi-layer framework to allow for in-depth focusing on the specific functioning of an agent's functions and how they interact with functions belonging to other levels of abstraction is obtained. This new FRAM approach improve the comprehensibility of the representation. Afterwards, Patriarca et al. (2017a) apply the proposed multi-layer framework to confirm that this FRAM approach allows to identify and understand the critical couplings as they happen between actors.

\section{Conclusions}

If the new FRAM approaches presented above are analysed, it is found that all the authors coincide in preserving the theoretical basis of FRAM for modeling complex systems. In general, it can be established that the proposed FRAM enhancements are aimed at facilitating its practical application with different purposes: to support the analysis of all critical paths of propagation of variability between functions; to recognize situations without control; to facilitate the identification of hazards or accidents analysis; to help understand the critical links while being related to the different agents or actors that intervene in the different hierarchical levels of the system. 
This study contributes to reaffirm the potential and the inherent need to establish strategies to actively combine the FRAM method with other methods. Its combined application provides complementary perspectives that can contribute to a more complete understanding and a more effective knowledge of the systems.

Multidisciplinary research in this field is necessary. In fact, Patriarca et al. (2017a) emphasize that innovative solutions to enhance the traditional FRAM are necessary. For that purpose, several of the methods exposed can be combined with the FRAM at the same time. According to Hollnagel (2012), FRAM is used to describe and understand how systems work. Therefore, future research should continue to advance the evolution the FRAM with the aim to facilitate the risk assessments in complex systems.

\section{Acknowledgements.}

We wish to thank the Spanish Ministry of Economy and Competitiveness for financing project BIA2016-79270-P, of which this paper forms a part, and the postdoctoral contract (FJCI-2015-24093). It is also important to acknowledge the Ministry of Education, Culture and Sports of the Government of Spain for it support through the predoctoral contracts (FPU 2016/03298)

\section{References}

BELlini, E., NESI, P., PANTALEO, G. y VENTURI, A. (2016). «Functional resonance analysis method based-decision support tool for urban transport system resilience management». In: 2016 IEEE International Smart Cities Conference (ISC2). Smart Cities Conference (ISC2), 2016 IEEE International, pp. 1-7.

BELLINI, E., CERAVOLO, P. y NESI, P. (2017). «Quantify resilience enhancement of UTS through exploiting Connected Community and Internet of Everything emerging technologies». ACM Ref. Format TBD ACM Trans Internet Technol Artic. 9.

DUAN, G., TIAN, J. y WU, J. (2015). «Extended FRAM by Integrating with Model Checking to Effectively Explore Hazard Evolution». Mathematical Problems in Engineering, 2015, pp. 1-11.

HADDAD, A. N. y ROSA, L. V. (2015). «Construction sustainability evaluation using AHP and FRAM methods». In IIE Annual Conference. Proceedings (p. 556). Institute of Industrial and Systems Engineers (IISE).
HEINRICH, H.W., (1931). Industrial Accident Prevention. Ed. McGraw Hill, NewYork.

HIROSE, T., SAWARAGI, T. y HORIGUCHI, Y. (2016). «Safety Analysis of Aviation Flight-Deck Procedures Using Systemic Accident Model». In: IFAC-PapersOnLine. Elsevier, pp. 19-24.

HOLLNAGEL, E. (1998). Cognitive reliability and error analysis method (CREAM). Ed. Elsevier.

HOLLNAGEL, E. (2004). Barriers and accident prevention: or how to improve safety by understanding the nature of accidents rather than finding their causes. Hampshire: Ashgate.

HOLLNAGEL, E., WODDS, D. y LEVESON, N. (2007). Resilience Engineering: Concepts and Precepts. Ashgate Publishing, Ltd.

HOLLNAGEL, E. (2012). FRAM: The functional resonance analysis method. Modelling complex socio-technical systems. CRC Press.

JENSEN, A. y AVEN, T. (2017). «Hazard/threat identification: Using functional resonance analysis method in conjunction with the Anticipatory Failure Determination method». Proceedings of the Institution of Mechanical Engineers, Part O: Journal of Risk and Reliability, 231(4), pp. 383-389.

LUNDBERG, J. y WOLTJER, R. (2013). «The Resilience Analysis Matrix (RAM): Visualizing functional dependencies in complex socio-technical systems». In 5th Resilience Engineering Association Symposium Soesterberg (The Netherlands), pp. 25-27.

PATRIARCA, R., BERGSTRÖM, J. y BERGSTROM, J. (2017a). «Modelling complexity in everyday operations: functional resonance in maritime mooring at quay». Cognition, Technology \& Work, 19(4), pp. 711-729.

PATRIARCA, R., BERGSTRÖM, J. y DI GRAVIO, G. (2017b). «Defining the functional resonance analysis space: Combining Abstraction Hierarchy and FRAM». Reliability Engineering \& System Safety, 165, pp. 3446.

PATRIARCA, R., DI GRAVIO, G. y COSTANTINO, F. (2017c). «A Monte Carlo evolution of the Functional Resonance Analysis Method (FRAM) to assess performance variability in complex systems». Safety Science, 91, pp. 49-60. 
PATRIARCA, R., DI GRAVIO, G., COSTANTINO, F. y TRONCI, M. (2017d). "The Functional Resonance Analysis Method for a systemic risk based environmental auditing in a sinter plant: A semi-quantitative approach». Environmental Impact Assessment Review, 63 , pp. 72-86.

PATRIARCA, R., DEL PINTO, G., DI GRAVIO, G. y COSTANTINO, F. (2018). «FRAM for Systemic Accident Analysis: A Matrix Representation of Functional Resonance». Int. J. Reliab. Qual. Saf. Eng. 1850001.

PATRIARCA, R., DI GRAVIO, G., GIULIO, D. G., y COSTANTINO, F. (2018). «FRAM for systemic accident analysis: a matrix representation of functional resonance». International Journal of Reliability, Quality and Safety Engineering, 25(01), 1850001.

PERROW, C. (1984). Normal accidents. Living with high risk technologies. Basico books. New York.

REASON, J. (1997). Managing the Risks of Organisational Accidents. Ashgate Publishing Ltd, Aldershot Hants, U.K.

ROSA, L.V., HADDAD, A.N. y DE CARVALHO, P.V.R. (2015). «Assessing risk in sustainable construction using the Functional Resonance Analysis Method (FRAM)». Cognition, Technology \& Work, 17(4), pp. 559-573.

ROSA, L.V., FRANCA, J.E.M., HADDAD, A.N. y CARVALHO, P.V.R., (2017). «A Resilience Engineering Approach for Sustainable Safety in Green Construction». Journal of Sustainable Development of Energy, Water and Environment Systems-JSDEWES, 5, pp. 480-495.
RUBIO-ROMERO, J. C., PARDO-FERREIRA, M. C., ROJAS-MARTÍNEZ, M., LÓPEZ-ARQUILLOS, A., y SUAREZ-CEBADOR, M. (2019). «Resilience Engineering: Concepts of the New Paradigm». In Engineering Digital Transformation (pp. 133-140). Springer, Cham.

STOPP, J. y DEKKER, S. (2012): «Are safety investigations pro-active?». Safety Science, 50, pp. 1422-1430.

TIAN, J., WU, J., YANG, Q. y ZHAO, T. (2016). «FRAMA: A safety assessment approach based on Functional Resonance Analysis Method». Safety Science, 85, pp. 41-52.

UNG, S.T. (2015). «A weighted CREAM model for maritime human reliability analysis». Safety Science, 72, pp. 144-152.

YANG, Q., TIAN, J. y ZHAO, T. (2017). «Safety is an emergent property: Illustrating functional resonance in Air Traffic Management with formal verification». Safety Science, 93, pp. 162-177.

ZHENG, Z. Y TIAN, J. (2015). «Bridging the gap between FRAM and safety practice by applying FSM and model checking». In: 2015 First International Conference on Reliability Systems Engineering (ICRSE). IEEE, pp. $1-6$.

ZHENG, Z., TIAN, J. y ZHAO, T. (2016). «Refining operation guidelines with model-checking-aided FRAM to improve manufacturing processes: a case study for aeroengine blade forging». Cognition, Technology \& Work, 18(4), pp. 777-791. 